Ibn Al-Haitham Jour. for Pure \& Appl. Sci. 32 (2) 2019

Ibn Al Haitham Journal for Pure and Applied Science Journal homepage: http://jih.uobaghdad.edu.iq/index.php/j/index

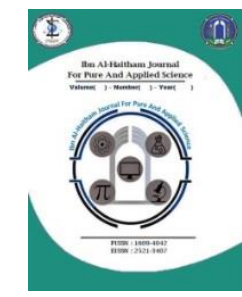

\title{
Study of the Anti-Diuretic Hormone (ADH) on End Stage Renal Failure Disease (ESRD) Pre-Hemodialysis in Iraqi Patients
}

\author{
Tiba A. Kh. Al-Taiee \\ Department of Chemistry, \\ College of Education for Pure \\ Science Ibn Al-Haitham, \\ University of Baghdad, \\ Baghdad, Iraq. \\ tibataiee92@gmail.com
}

Nawal M.J. Al-Shammaa

Department of Chemistry,

College of Education for Pure

Science Ibn Al-Haitham,

University of Baghdad,

Baghdad, Iraq.

\author{
Adnan Abduladheem Aljber \\ Ministry of Health, Medical City \\ Hospital, Baghdad, Iraq.
}

Article history: Received 25 June 2018, Accepted 5 August 2018, Publish May 2019

Doi: 10.30526/32.2.2135

\begin{abstract}
Chronic renal disease (CRD) is a pathophysiologic process with multiple etiologies, resulting in the inexorable attrition of Nephron number and function and frequently leading to end-stage renal disease (ESRD). In turn, ESRD represents a clinical state or condition in which there has been an irreversible loss of endogenous renal function, of a degree sufficient to render the patient permanently dependent upon renal replacement therapy (dialysis of transplantation) in order to avoid life threatening uremia, reflecting a dysfunction of all organ systems as a result of untreated or under treated acute or chronic renal failure. The current study was involved 80 patients, the age range within 25-70 years, selected sample of patients who attend Iraqi center of kidney dialysis, Baghdad Teaching Hospital and Al-Yarmok Teaching Hospital. All the patient's body mass index [BMI] were measured serum anti diuretic hormone $\mathrm{ADH}$ was assessed using enzyme linked immunosorbent kit [Elisa] while urea, creatinine, albumin, hemoglobin were determined by spectrophotometer (PD-303), and sodium, potassium, chloride were determined by Electrolyte analyzer 9180.These patients were divided in two group B (40 patients) as pre dialysis with ESRD, and group A (40) healthy control. Results showed non-significant elevations in ADH levels in the patient group compared with the control group, while highly significant increase in urea, creatinine and albumin levels in in the patient group compared with the control group, also highly significant decrease in hemoglobin comparing with the control group. Also, it was observed nonsignificant decrease in sodium, non-significant increase in potassium and highly significant increase in chloride when comparing with the control group.
\end{abstract}

Keywords: Anti Diuretic Hormone (ADH), Kidney Function (Urea. Creatinine, albumin), Hemoglobin and Electrolyte (sodium, potassium, chloride). 


\section{Ibn Al-Haitham Jour. for Pure \& Appl. Sci. 32 (2) 2019}

\section{Introduction}

Antidiuretic hormone (ADH) is a hormone secreted by the posterior lobe of the pituitary gland, in the brain. ADH moves in the blood and reaches to its target organ, the kidney. And it is a key hormone in human body serving important physiological functions such as homeostasis of fluid balance and regulation of the endocrine stress response. Two basic functions of $\mathrm{ADH}$, the first, is to increase the amount of solute-free water reabsorbed back into the circulation from the filtrate in the kidney tubules of the nephrons. The second, function is that $\mathrm{ADH}$ narrowing the arteries, which increases peripheral vascular resistance and raises arterial blood pressure [1]. ESRD is a clinical condition in which the renal loses its functions, making the patient dependent on renal dialysis to avoid accumulation of waste and toxins in the blood that lead to loss of patient life. There are several reasons to ESRD are atherosclerosis, immune diseases, kidney disorders, painkillers, the most important cause of this disease is hypertension [2]. Hemodialysis is the process by which all the toxins and impurities in the patient's blood are removed and then braced to the body. This process is done two or three times a week for 3-4 hours per session. It may help balance body fluids with the necessary minerals, sodium, potassium, calcium and chloride and also help control blood pressure [3]. Urea is a small molecule that dissolves in water, it consists of two nitrogen atoms, which is the final produce of nitrogen and protein metabolism, and generates in the liver. Through glomerulus, urea is filtered and reuptake in nearby and distant nephrons. In nearby tubule a great portion of the filtered of urea is absorbed in medulla collecting duct [4, 5]. Creatinine is a waste product from the normal breakdown of muscle tissue. As creatinine is produced, it's filtered through the kidneys and excreted in urine [6]. Albumin is a protein that makes up a big proportion of the plasma proteins found in the blood in huge amounts, which are output in liver. Blood volume is organized by serum albums through the preservation of osmotic pressure and it is therefore a key factor in controlling the interchange of water among interstitial vacuum and plasma [7]. Anemia occurs when we have a decreased level of hemoglobin in red blood cells (RBCs) caused by iron shortage in the blood, which in turn leads to a lowering in the formed of heme. Malnutrition, frequent blood loss, renal failure, sickle cell anemia or thalassemia [8]. The renal possesses a turn in regulation of chloride ion, when the appearance of any disorder or imbalance in level electrolyte means that is to the presence of damage in the renal, or other reasons impact to the disability of the kidneys to preserve the balance of $\mathrm{Cl}^{-}$as intensive drought or diabetes [9]. Sodium participates in organizing water balance in the body, this leads the water is pumped inside the cell, it also plays a role in balancing acid base, and in the body's osmotic balance, which contributes to plasma volume regulation. Although there are several important roles of sodium in the body, but the abundance and quality in the renal patients is mischievous because of the disability of the kidneys to filter the sodium ions and other excess fluids, so the existing of any disorder in renal function occurs unbalance in sodium levels $[10,11]$. The body utilizes potassium that is needed, and removes the surplus of its need by the renal via the bloodstream. But when there is a lack of kidney effectiveness, therefore, its inability to filter this surplus from potassium leads to high levels of $\mathrm{K}+$ in the bloodstream [12]. The aim of the present work is to investigate the effect of Anti Diuretic Hormone (ADH) on kidney functions (Urea, Creatinine, Albumin), Hemoglobin, Electrolyte (sodium, potassium, chloride) on End Stage Renal Failure Disease (ESRD) in pre hemodialysis. 
Ibn Al-Haitham Jour. for Pure \& Appl. Sci. 32 (2) 2019

\section{Material and Methods}

\subsection{Patients}

The current study was applied on 80 patients, the age was ranged within 25-70 years, selected sample of patients who attend Iraqi dialysis center, Baghdad Teaching Hospital and Al-Yarmok Teaching Hospital for the period from October 2017 to January 2018.Body mass index BMI was measured for all patients. Serum anti diuretic hormone ADH was assessed using enzyme linked immunosorbent kit [Elisa] while urea, creatinine, albumin, hemoglobin was determined by spectrophotometer (PD-303), and sodium, potassium, chloride was determined by electrolyte analyzer 9180.Two groups, one included pre dialysis with ESRD (group B), and group A as healthy control.

\subsection{Blood Sample Collection}

Five $\mathrm{ml}$ of venous blood sample was obtained from each subject. The blood samples which were collected from all subjects were transferred into gel tube, allowed to stand for 25 minutes at room temperature then centrifuged at $4000 \mathrm{rpm}$ for 10 minutes. The resulting serum suppurated and frozen at $-40^{\circ} \mathrm{C}$ till used for estimation of levels $\mathrm{ADH}$, Urea, Creatinine, Albumin, hemoglobin, electrolyte $\left(\mathrm{Na}^{+}, \mathrm{CL}^{-1}, \mathrm{~K}^{+}\right)$.

\subsection{Statistical Analysis}

The Statistical analysis system SPSS version 20, T-test and chi- square program used was to affect difference factors in study parameters. In this study correlation coefficient estimated between different parameter [13].

\section{Results and Discussion}

Results showed a non-significant increase in GB when comparing with GA in ADH, while highly significant increase in GB comparing with GA in urea, creatinine and albumin, also highly significant decrease in GB when comparing with GA in hemoglobin as shown in Table 1, and Figure 1. Earlier data showed to patients ESRD before dialysis sera ADH, urea and creatinine levels are higher than healthy control. Previous studies, agree with data to ADH, urea and creatinine levels [14-16]. subsequent data confirm this finding and indicated that the elevated levels of ADH were related to osmolality due to increased concentration of salts and proteins in the blood increases the storage of water in the body and thus leads to lower kidney function and increased secretion of $\mathrm{ADH}$. This means that increased osmolality leads to a significant increase in ADH levels because osmolality is the main regulator of ADH release $[17,18]$. while urea and creatinine levels are related to glomerular filtration rate (GFR), due to the low number of nephrons working in the kidneys, which in turn reduce the rate of glomerular filtration (GFR), thus makes the kidneys unable on blood purification and removed waste so that the accumulation of waste and toxic chemicals in the blood, causing dysfunction in the kidneys as called renal failure [19, 20]. Also data showed of observed albumin and hemoglobin levels are lower than healthy control. These results agree with previous studies to albumin and hemoglobin levels of which have obtained are study Suda, et al., [21] and Astor, et al., [22]. Data confirm that the reduction level of albumin is related with reduced renal function, because the kidneys are disposed of fluid and waste in the body. When renal syndrome occurs, the kidneys stop functioning. Thus, albumin is lost in the urine, leading to a decrease in the level of albumin in the blood [23]. While reduction level of 
hemoglobin is related with anemia occurs in patients with renal failure because the kidneys are responsible for the secretion of the hormone erythropoietin (EPO), which is responsible for the formation of red blood cells. When kidney function is lost, thus, the number of red blood cells production decreases, causing a decrease in the level of hemoglobin responsible for anemia [24, 25]. Results in Table 2, and Figure 2, observed non-significant decrease in $G_{B}$ when comparing with $G_{A}$ in sodium and non-significant increase in $G_{B}$ when comparing with $G_{A}$ in potassium, while highly significant increase in $G_{B}$ when comparing with $G_{A}$ in chloride. The data show a decrease in sodium level before dialysis compared with health control. Previous studies support these findings [26-28]. Low sodium in the blood leads to the kidneys secretion angiotensin which causes the adrenal cortex to secrete aldosterone, the latter induces the renal tubules to reabsorb sodium from the glomerular filtrate. when renal dysfunction occurs, the amount of water in the blood increases, leading to a decrease in the blood volume, where salinity is becoming more sensitive, thus lowering the level of sodium which works on high blood pressure, because sodium is responsible for regulating blood pressure [29]. While potassium levels in the blood increase due to Potassium accumulates in the blood due to the main decrease in kidney function, in the event of kidney failure kidneys could not get rid of the amount of potassium overload the body's need, so there is an excess of potassium levels [30]. Also increase chloride levels in pre dialysis due to the body's loss of large quantities of fluids, which are free of chloride, leading to high concentration of ions in the body as in drought, thus reducing the flow of renal blood, and due also to increased metabolic acid in the blood as a result of the inability of the kidneys to get rid of excess acidity and therefore occur hyperchloremia [31].

Table 1. Level of ADH, Urea, Creatinine, Albumin and Hemoglobin with ESRD patients and control group.

\begin{tabular}{|c|c|c|c|}
\hline Parameters & Group A $\left(\mathbf{G}_{\mathbf{A}}\right)$ & Group B $\left(\mathbf{G}_{\mathbf{B}}\right)$ & P-value \\
\hline ADH Pg/ml & $32.33 \pm 3.88$ & $35.21 \pm 5.23$ & 0.150 \\
\hline Urea mg/dl & $30.20 \pm 5.02$ & $104.78 \pm 40.1$ & 0.001 \\
\hline Creatinine mg/dl & $3.36 \pm 0.76$ & $6.61 \pm 2.30$ & 0.001 \\
\hline Albumin g/l & $4.43 \pm 0.59$ & $3.51 \pm 0.47$ & 0.001 \\
\hline Hemoglobin g/l & $9.96 \pm 0.27$ & $7.89 \pm 0.99$ & 0.001 \\
\hline
\end{tabular}

$(\mathrm{P} \leq 0.05)$ significant $(\mathrm{S}),(\mathrm{P} \geq 0.05)$ non-significant $(\mathrm{N} . \mathrm{S}),(\mathrm{P} \leq 0.01)$ highly significant $(\mathrm{H} . \mathrm{S})$. 
Ibn Al-Haitham Jour. for Pure \& Appl. Sci. 32 (2) 2019

Table 2. Level of Sodium, Potassium and Chloride with ESRD patients and control group.

\begin{tabular}{|c|c|c|c|}
\hline Parameters & Group A $\left(\mathbf{G}_{\mathbf{A}}\right)$ & Group B $\left(\mathbf{G}_{\mathbf{B}}\right)$ & P-value \\
\hline $\mathbf{N a}^{+} \mathbf{~ m m o l} / \mathbf{L}$ & $139.5 \pm 2.67$ & $122.57 \pm 7.70$ & 0.558 \\
\hline $\mathbf{K}^{+} \mathbf{m m o l} / \mathbf{L}$ & $3.93 \pm 0.34$ & $4.33 \pm 0.96$ & 0.140 \\
\hline $\mathbf{C l}^{-1} \mathbf{~ m m o l} / \mathbf{L}$ & $100.6 \pm 2.36$ & $122.57 \pm 7.70$ & 0.001 \\
\hline
\end{tabular}

$(\mathrm{P} \leq 0.05)$ significant $(\mathrm{S}),(\mathrm{P} \geq 0.05)$ non-significant (N.S), $(\mathrm{P} \leq 0.01)$ highly significant (H.S).

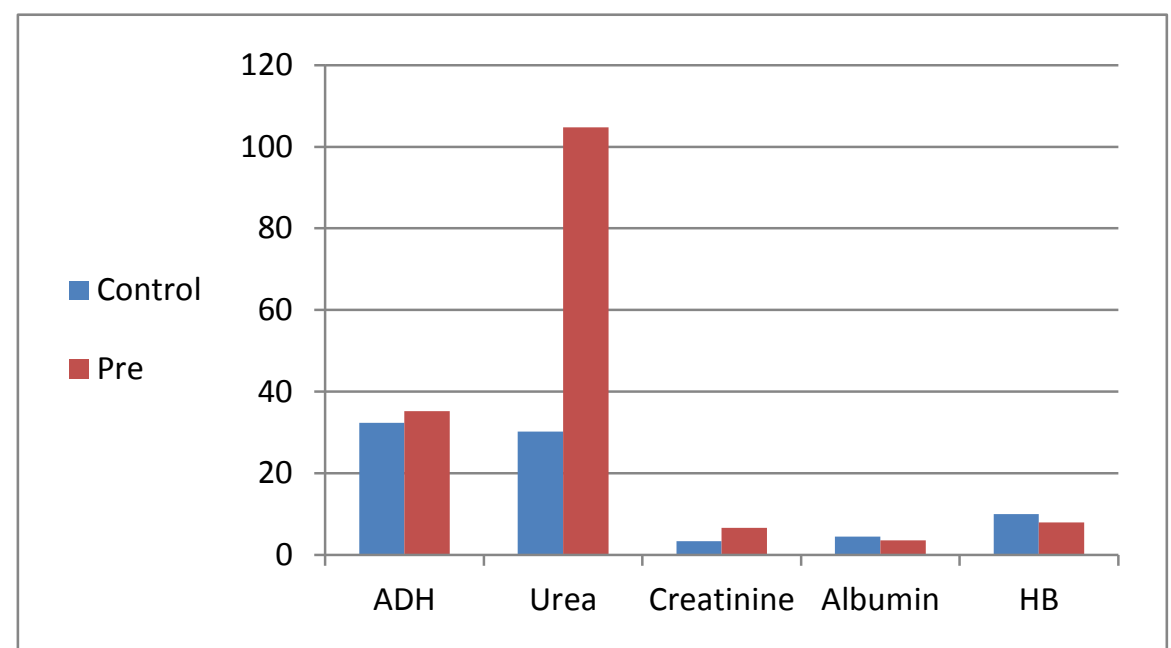

Figure 1. comparison between patient ESRD and control group for ADH, Urea, Creatinine, Albumin and Hemoglobin.

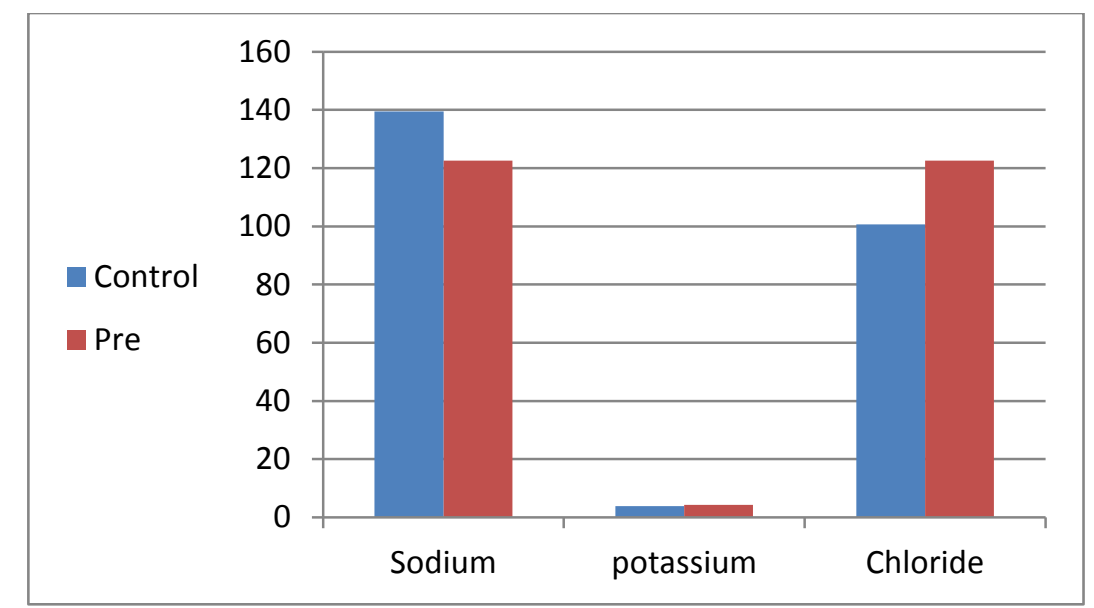

Figure 2. Comparison between patient ESRD and control group for Sodium, Potassium and Chloride. 


\section{Conclusion}

In this study, serum $\mathrm{ADH}$ and $\mathrm{K}+$ levels were non-significant increase in pre dialysis. Serum Urea, creatinine, albumin, $\mathrm{Cl}^{-}$levels ware non-significant increase in pre dialysis, serum hemoglobin levels were highly significant decrease in pre dialysis, and serum $\mathrm{Na}+$ levels was non-significant decrease in pre dialysis compared to healthy control.

\section{References}

1. Richard, I.G.H.; Neil, A.H. Essential Endocrinology and diabetes. $6^{\text {th }}$ edition, WileyBlackwell. 2012. ISBN:978-1-444-33004-5.

2. Sud, M.; Tangri, N.; Levin, A.; Pintilie, M.; Levey, A.S.; Naimark, D.M. CKD stage at nephrology referral and factors influencing the risks of ESRD and death. American Journal of Kidney Diseases. 2014, 63, 928-936.

3. Ramaprabha, P.; Bhuvaneswari, T.; Kumar, R.A. Coagulation profiles an indicator of vascular haemostatic function in chronic renal failure patients who are on renal dialysis. Scholars Journal of Applied Medical Sciences.2014, 2, 2B, 592-595.

4. Kottegoda, N.; Sandaruwan, C.; Priyadarshana, G.; Siriwardhana, A.; Rathnayake, U.A.; Berugoda-Arachchige, D.M.; Amaratunga, G.A.J. Urea-Hydroxyapatite Nanohybrids for Slow Release of Nitrogen. ACS Nano.2017, 11, 1214-1221.

5. Danziger, J.; Zeidel, M.; Parker, M.J. Renal Physiology: A Clinical Approach. $1^{\text {st }}$ Edition Lippincott Williams \& Wilkins. 2011.

6. Bamanikar, S.A.; Bamanikar, A.A.; Arora, A. Study of Serum urea and Creatinine in Diabetic and nondiabetic patients in a tertiary teaching hospital. The Journal of Medical Research. 2016, 2, 12-15.

7. Roberts, I.; Blackhall, K.; Alderson, P.; Bunn, F.; Schierhout, G. Human albumin solution for resuscitation and volume expansion in critically ill patients. Cochrane database of systematic reviews. 2011, 11, 1-42.

8. Astor, B.C.; Muntner, P.; Levin, A.; Eustace, J.A.; Coresh, J. Association of kidney function with anemia: The Third National Health and Nutrition Examination Survey (1988-1994). Archives of internal medicine. 2002, 162, 1401-1408.

9. Zumdahl, S.S.; Donald, J.D. Chemical principles. McDougal Littell/Houghton Mifflin, $8^{\text {th }}$ Edition, USA. 2016

10. Gatti, M.; Tokatly, I.V.; Rubio, A. Sodium: a charge-transfer insulator at high pressures. Physical review letters. 2010, 104, 1-13.

11. Rakova, N.; Kitada, K.; Lerchl, K.; Dahlmann, A.; Birukov, A.; Daub, S.; Kopp, C.; Pedchenko, T.; Zhang, Y.; Beck, L.; Johannes, B. Increased salt consumption induces body water conservation and decreases fluid intake. The Journal of clinical investigation. 2017, 127, 1932-1943.

12. Waziri, I.; Fugu, M.B.; Ndahi, N.P. Solvent-free synthesis, characterization and antimicrobial studies of calcium and potassium complexes with some cephalosporin antibiotics. Research Journal of Chemical Sciences. 2018, 8, 7-14.

13. Daniel, W.W.; Cross, C.L. Biostatistics: a foundation for analysis in the health sciences. $10^{\text {th }}$ Edition, Wiley, Wiely and Sons Inc. 2013

14. Nakayama, M.; Yamada, K.; Nakano, H.; Miura, Y. Stimulated secretion of arginine vasopressin during hemodialysis in patients with hemodialysis hypotension. Nephron. 1998, 79, 488-489. 


\section{Ibn Al-Haitham Jour. for Pure \& Appl. Sci. 32 (2) 2019}

15. Chielle, E.O.; Rigon, K.A.; Arcari, I.A.; Stein, V.; Santos, G.A.D. Influence of hemodialysis on the plasma concentration of adenosine deaminase in patients with chronic kidney disease. Jornal Brasileiro de Patologia e Medicina Laboratorial. 2015, 51,153-157.

16. Amin, N.; Mahmood, R.T.; Asad, M.J.; Zafar, M.; Raja, A.M. Evaluating urea and creatinine levels in chronic renal failure pre and post dialysis: a prospective study. Journal of cardiovascular disease. 2014, 2, 1-4.

17. Ettema, E.M.; Zittema, D.; Kuipers, J.; Gansevoort, R.T.; Vart, P.; De Jong, P.E.; Westerhuis, R.; Franssen, C.F. Dialysis hypotension: a role for inadequate increase in arginine vasopressin levels? A systematic literature review and meta-analysis. American journal of nephrology. 2014, 39, 100-109.

18. Ettema, E.M.; Heida, J.; Casteleijn, N.F.; Boesten, L.; Westerhuis, R.; Gaillard, C.A.; Gansevoort, R.T.; Franssen, C.F.; Zittema, D. The effect of renal function and hemodialysis treatment on plasma vasopressin and copeptin levels. Kidney international reports. 2017, 2, 410-419.

19. Delanaye, P.; Cavalier, E.; Pottel, H. Serum creatinine: not so simple! Nephron. 2017, 136, 302-308.

20. Israa, A.; Mohammed, J. A study of some biochemical parameters in blood of patients with chronic renal failure. Journal of Basrah Researches Sciences. 2013, 39, 4, 20-32.

21. Suda, T.; Hiroshige, K.; Ohta, T.; Watanabe, Y.; Iwamoto, M.; Kanegae, K.; Ohtani, A.; Nakashima, Y. The contribution of residual renal function to overall nutritional status in chronic haemodialysis patients. Nephrology Dialysis Transplantation. 2000, 15, 396-401.

22. Astor, B.C.; Muntner, P.; Levin, A.; Eustace, J.A.; Coresh, J. Association of kidney function with anemia: The Third National Health and Nutrition Examination Survey (1988-1994). Archives of internal medicine. 2002, 162, 1401-1408.

23. Eriguchi, R.; Obi, Y.; Rhee, C.M.; Chou, J.A.; Tortorici, A.R.; Mathew, A.T.; Kim, T.; Soohoo, M.; Streja, E.; Kovesdy, C.P.; Kalantar- Zadeh, K. Changes in urine volume and serum albumin in incident hemodialysis patients. Hemodialysis International. 2017, 21, 507-518.

24. Hakim, Y.A.; Abbas, A.A.; Khali, A.; Mustafa, H.I.A. The effect of hemodialysis on hemoglobin concentration, platelets count and white blood cells count in end stage renal failure. International Journal of Medical Research and Health Sciences. 2016, 5, 22-35.

25. Geller, A.B.; DeVita, M.V.; Marku- Podvorica, J.; Rosenstock, J.L.; Panagopoulos, G.; Michelis, M.F. Increase in post- dialysis hemoglobin can be out of proportion and unrelated to ultrafiltration. Dialysis \& Transplantation. 2010, 39, 57-62.

26. Ravel, V.A.; Streja, E.; Mehrotra, R.; Sim, J.J.; Harley, K.; Ayus, J.C.; Amin, A.N.; Brunelli, S.M.; Kovesdy, C.P.; Kalantar-Zadeh, K.; Rhee, C.M. Serum sodium and mortality in a national peritoneal dialysis cohort. Nephrology Dialysis Transplantation. 2016, 32, 1224-1233.

27. Luo, J.; Brunelli, S.M.; Jensen, D.E.; Yang, A. Association between serum potassium and outcomes in patients with reduced kidney function. Clinical Journal of the American Society of Nephrology. 2016, 11, 90-100.

28. Marques, F.O.; Libório, A.B.; Daher, E.F. Effect of chloride dialysate concentration on metabolic acidosis in aintenance hemodialysis patients. Brazilian Journal of Medical and Biological Research.2010, 43, 996-1000. 
29. Dekker, M.J.E.; Marcelli, D.; Canaud, B.; Konings, C.J.A.M.; Leunissen, K.M.; Levin, N.W.; Carioni, P.; Maheshwari, V.; Raimann, J.G.; van der Sande, F.M.; Usvyat, L.A. Unraveling the relationship between mortality, hyponatremia, inflammation and malnutrition in hemodialysis patients: results from the international MONDO initiative. European journal of clinical nutrition. 2016, 70, 779-784.

30. Yusuf, A.A.; Hu, Y.; Singh, B.; Menoyo, J.A.; Wetmore, J.B. Serum potassium levels and mortality in hemodialysis patients: a retrospective cohort study. American journal of nephrology. 2016, 44, 179-186.

31. Nagami, G.T. Hyperchloremia-Why and how. Nefrologia. 2016, 36, 347-353. 